Journal of Bangladesh Academy of Sciences, Vol. 37, No. 1, 43-50, 2013

\title{
MORPHOLOGY AND METALLURGICAL STUDIES ON A FEW ARCHEOLOGICAL SAMPLES FOUND IN OLD FORGES IN JAPAN
}

\author{
A. K. DAS AND I. KAMAL \\ Institute of Nuclear Science and Technology, Atomic Energy Research Establishment, \\ Ganakbary, Savar, Dhaka, Bangladesh
}

\begin{abstract}
An investigative study was carried out on a few archeological samples collected from very old and abandoned forges situated near Izumo city of Shimane prefecture in Japan. The samples were named as Koedo Tatara (in Japanese) and identified as Koedo-21, Koedo-39 and so on, as per the number of well dug for hunting the samples. In the naked eye observation the samples were looked like the rusted iron lump of heterogeneous shapes having brownish and blackish colours. A variety of minerals such as ilmenite $\left(\mathrm{FeO} . \mathrm{TiO}_{2}\right)$, fayalite $\left(2 \mathrm{FeO} . \mathrm{SiO}_{2}\right)$, hercinite $\left(2 \mathrm{FeO} . \mathrm{Al}_{2} \mathrm{O}_{3}\right)$ along with ferrite $(\mathrm{FeO})$ were identified by observing the structural morphologies in optical microscopic study. EDS (Energy dispersive X-ray spectroscopy) study revealed that most of the samples were the composite of iron oxides along with a few amount of carbon, silica $\left(\mathrm{SiO}_{2}\right)$, alumina $\left(\mathrm{Al}_{2} \mathrm{O}_{3}\right)$, rutile $\left(\mathrm{TiO}_{2}\right)$ etc. Vickers micro-hardness test revealed that several samples were moderately hard and some others were nonmetallic oxides and not fit for hardness measurement. It was realized that the samples were the by-product of old blacksmith's forges which were dismantled for hundreds of years in the natural environment.
\end{abstract}

Key words: Morphology, Koedo-tatara, Artifact, Minerals, Micro-hardness

\section{INTRODUCTION}

Scientific researches on archeological objects are most significant for understanding the evolution of human civilization. Ancient metallurgy and metallic products are also very important to explore the culture and tradition developed in a nation of a particular region (Sherby 1999). History and literature bear the evidence that in different parts of the world different types of metallic swords were used as weapons from very early times (Barnett 2009, Reibold et al. 2006). Among others the Japanese sword and the Damascus sword have attracted the special attention of materials scientists due to their extraordinary structural and mechanical properties. Especially the sharp cutting edge, beautiful wavy banding pattern, hardness and durability of those swords are noteworthy (Mapelli et al. 2007). In Japan the swords were prepared by the traditional tatara method since hundreds of years back and the quality of the sword (steel) has been proved to be unique. It is also believed that tatara is a unique method of producing iron/steel which is not possible in modern industry. Because, some special techniques are 
employed in this traditional (hand made) process which are difficult to do by machines (Takami et al. 2010).

During the World War-II many of the blacksmiths of Japan involved in tatara were killed and their establishments were destroyed completely. Consequently the production of Japanese sword was stopped. But, due to its long history and aesthetic value the Japanese sword has gained the status of a symbol of aristocracy in Japanese society (Das et al. 2010). The present generations of ancient blacksmiths are trying to produce the Japanese sword as like as the traditional one for preserving their tradition and cultural heritage. Metallurgists and materials scientists are also very curious to know the secrecy behind its preparation process. How did they achieve such a quality product in that ancient period of time? The swords made today are not of course, intended for its actual purpose but its quality and design have conferred the dignity of an aesthetic object to it in the Japanese society (Leon et al. 1887).

\section{MATERIALS AND METHODS}

To explore the historical background and to observe the technical skill of the ancient blacksmiths concerned with tatara a number of samples were collected from the mountainous region near Izumo city with the cooperation of Izumo City Corporation, Japan. It has been belived that many blacksmiths lived in that region and produced iron/steel for fabricating traditional Japanese swords in 16 - 18th century (Das et al. 2010). In that selected area several wells were dug and different kinds of iron/steel blocks of different sizes, charcoal etc. covered with mud were collected for the study.

The collected samples were cleaned by brush primarily and dried in sun. Then the samples were cut into small pieces by a diamond cutter for making it suitable for different experimental studies. Then the samples were grinded and polished successively by fine to finer grained emery paper. For obtaining very smooth and mirror like surface the samples were polished by silica gel solution finally. Chemical etching has also been performed using nital solution for getting the clear images, where necessary. The primary observation for micro-structural (morphological) study was carried out by optical microscopy. The SEM-EDS study was performed to determine the minerals and elemental contents in the specimen as well as to identify the structural morphology. Carbon coating were put on a few samples prior to the experiment for making the samples suitable (conducting) for EDS study. Since all the samples were iron-based, carbon content was the vital factor to form its structural morphology and hardness. So the authors also measured the micro Vickers hardness of the samples and compared the results with reference data. All the experimental studies were performed in the Department of Materials Science, Interdisciplinary Faculty of Science and Engineering, Shimane University, Japan. 


\section{RESULTS AND DISCUSSION}

At first all the samples were observed physically by naked eye and ordinary photographs were taken by optical camera. Then the samples were cut and polished and prepared for further experimental studies such as optical microscopy, EDS and Vickers micro-hardness test subsequently.

Naked eye observation: The specimens were examined by naked eye for observing its physical shape, size, weight, colour etc. Most of the samples looked like a lump of solidified slug of iron with heterogeneous shape having brownish or blackish colours. Figs 1(a), 2(a), 3(a), 4(a), 5(a) and 6(a) showed the physical appearance of Koedo-21, Koedo-39, Koedo-40, Koedo-47, Koedo-49 and Koedo-50 samples, respectively. The physical weight of these samples was like metal except Koedo-21, which was a composite of oxides and its weight was comparatively light.

Table 1. Minerals content (mass\%) found in Koedo-tatara determined by EDS study.

\begin{tabular}{ccccccc}
\hline Sample & Koedo-21 & Koedo-39 & Koedo-40 & Koedo-47 & Koedo-49 & Koedo-50 \\
\hline Carbon & --- & 5.22 & 3.74 & 2.18 & 2.84 & 4.77 \\
$\mathrm{Al}_{2} \mathrm{O}_{3}$ & 3.96 & --- & 0.92 & 1.24 & --- & 5.36 \\
$\mathrm{SiO}_{2}$ & 19.56 & 1.25 & 1.6 & 1.22 & 1.68 & 3.64 \\
$\mathrm{MgO}$ & 2.39 & --- & --- & --- & --- & --- \\
$\mathrm{K}_{2} \mathrm{O}$ & 1.80 & --- & --- & --- & -- & --- \\
$\mathrm{P}_{2} \mathrm{O}_{5}$ & --- & --- & --- & --- & 0.10 & 0.42 \\
$\mathrm{CaO}$ & 1.38 & --- & --- & --- & --- & 0.20 \\
$\mathrm{TiO}_{2}$ & 20.96 & --- & --- & --- & --- & -- \\
$\mathrm{MnO}^{-30}$ & 2.88 & --- & --- & --- & --- & 0.93 \\
$\mathrm{SO}_{3}$ & --- & --- & --- & 0.65 & 95.38 & 84.68 \\
$\mathrm{FeO}_{\mathrm{Total}}$ & 47.06 & 93.53 & 93.73 & 94.63 & $100 \%$ & $100 \%$ \\
\hline
\end{tabular}

Optical microscopic study: Optical microscopic images were taken from different parts of the specimen at different magnification power for observing the structural morphology contained in it. Figs 1(b) and 1(c) showed the internal morphology of Koedo-21 specimen. It appeared that small sizes of metallic flakes were scattered in a non-metallic bulk. Internal structure of this specimen demonstrated that it was a block of iron-slug formed at the time of smelting raw materials in the tatara furnace. Figs 2(b) and 2(c) showed the morphological views of Koedo-39 specimen. Koedo-40 contained metallic iron in the middle part of the sample covered by a thick boundary of rust. Figs. 3(b) and 3(c) showed the structural morphology of Koedo-40 specimen. Figs 4(b) and 4(c) showed the morphology of Koedo-47. Figs 5(b) and 5(c) showed the morphology of Koedo-49. Figs 6(b) and 6(c) showed the morphology of Koedo-50. The major 
morphology of all the specimens resembled to that of the cast iron except Koedo-21. The details of minerals contents are depicted in the SEM-EDS study section.

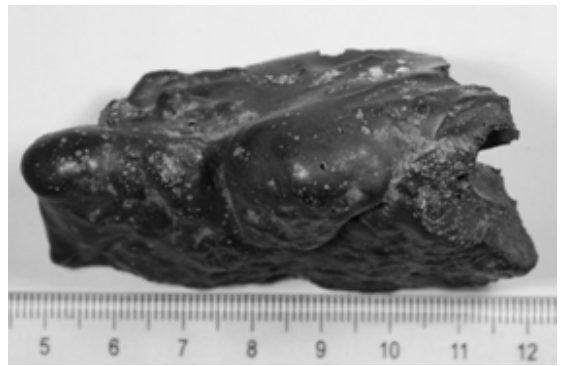

Fig. 1(a). Photograph of Koedo-tatara-21.

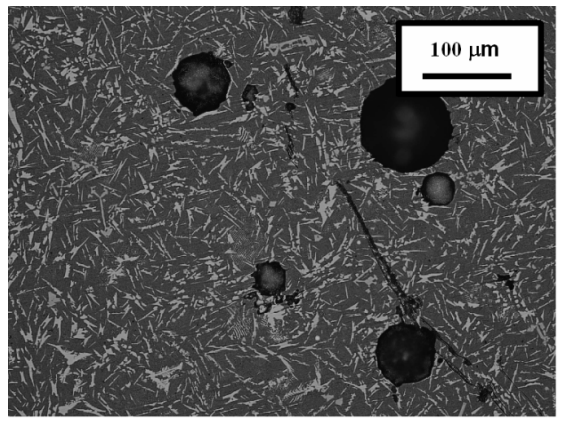

Fig. 1(b). Small size metal flakes are scattered in the oxide matrix. Morhology: mixture of ilmenite, rutile, fayalite and hercinite.

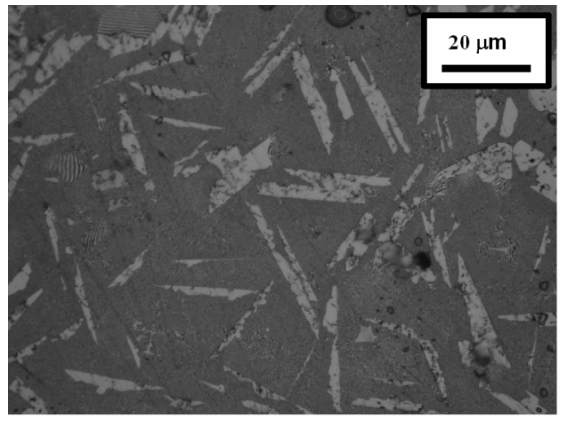

Fig. 1(c). Magnified view of Fig.1(b). Scattered metal flakes are seen clearly.

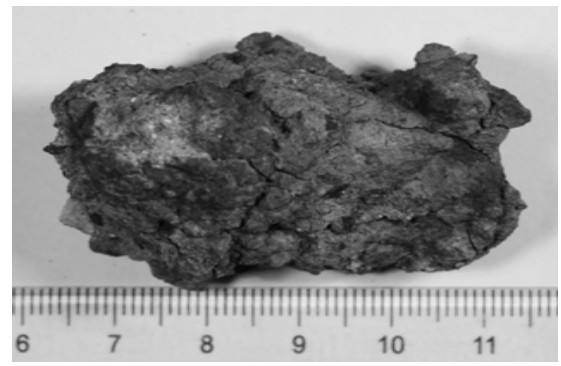

Fig. 2(a). Photograph of the Koedo-tatara-39.

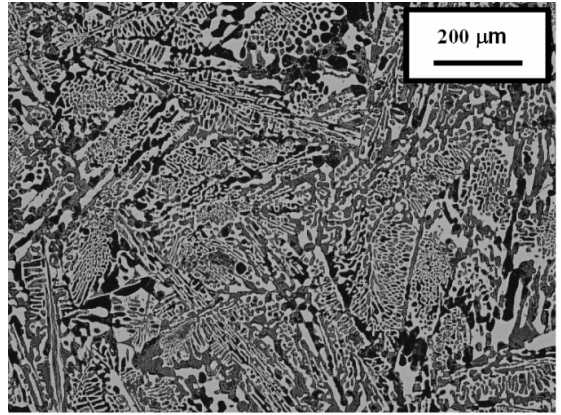

Fig. 2(b). Cross sectional view of Koedo-39. Morphology: hypereutectic cast iron and fayalite.

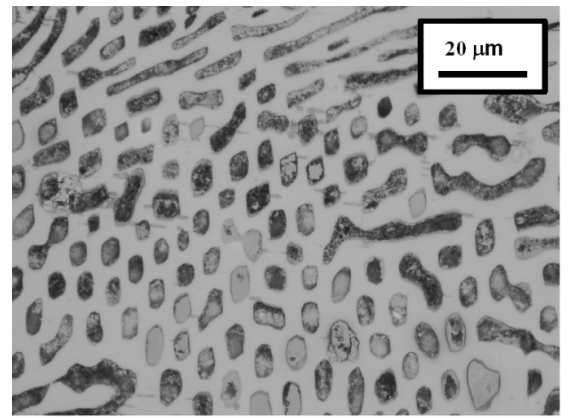

Fig. 2(c). Cross sectional view of Koedo-39 (magnified).

SEM-EDS study: The SEM-EDS study was performed on each specimen individually. The data were taken from at least ten different points of each sample. The average quantity of minerals found in each specimen is presented in Table 1. 


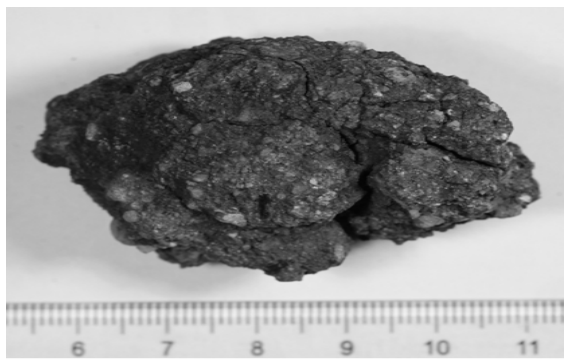

Fig. 3(a). Photograph of the Koedo-40 sample.

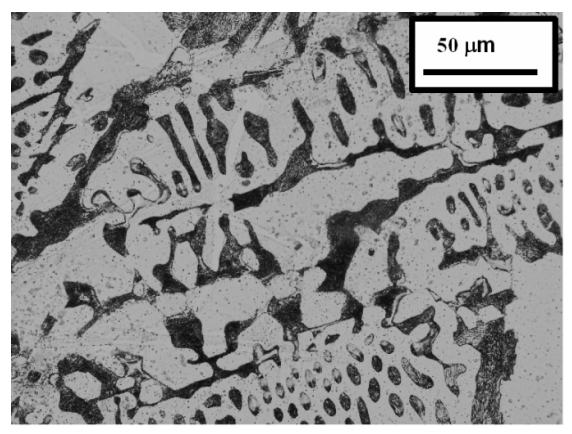

Fig. 3(b). Cross sectional view of Koedo-40. Bright part is metallic iron and the dark part is nonmetallic oxide.

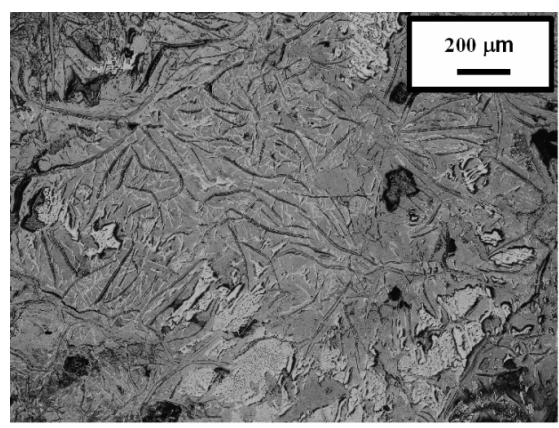

Fig. 3(c). Cross sectional view-2 of Koedo-40. Morphology: hypereutectic cast iron, fayalite and hercinite.

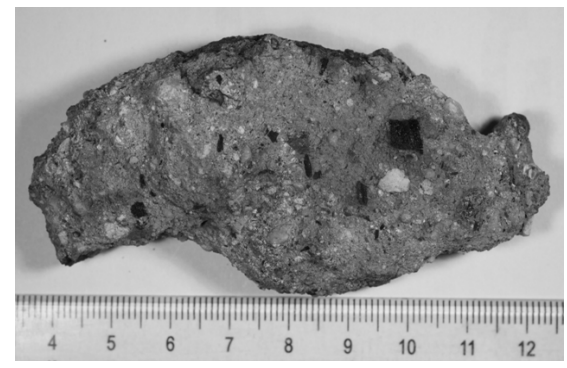

Fig. 4(a). Photograph of the Koedo-47 sample.

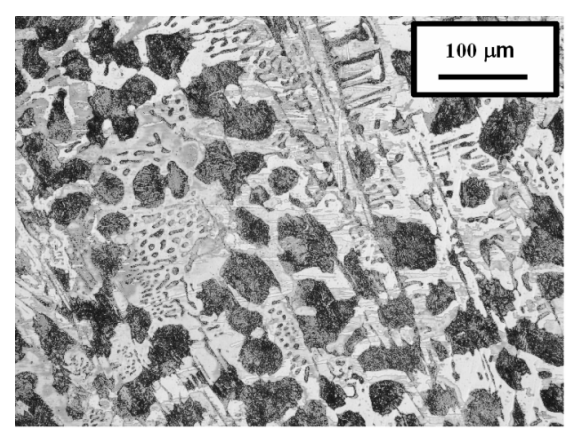

Fig. 4(b). Cross sectional view of Koedo-47. Combination of metallic iron and oxides are found.

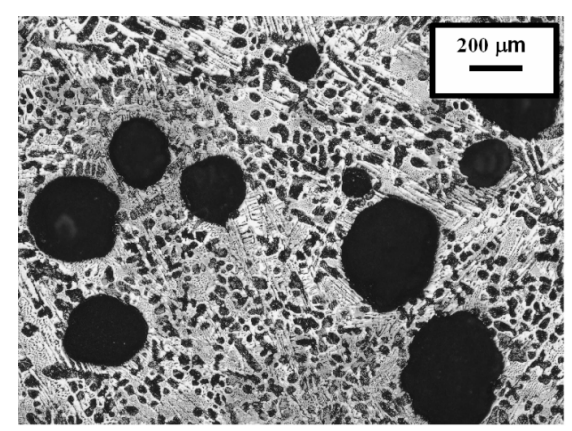

Fig. 4(c). Cross sectional view of Koedo-47 taken from different position. Black circular areas are holes. Morphology: hypereutectic cast iron fayalite and hercinite.

Koedo-21: This specimen was an oxide rich material and poor electric conductor. So prior to the EDS experiment carbon-vapour polishing was performed by putting the sample in a JEOL vacuum carbon coating machine for making it conductive. A variety of metallic oxides were found in the specimen and listed in Table 1. In aggregate the minerals contents were a mixture of ilmenite, rutile, fayalite and hercinite (Mac et al. 1961, Sidney 1998). 


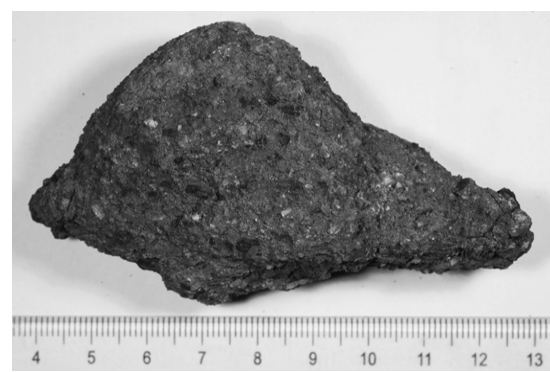

Fig. 5(a). Photograph of the Koedo-49 sample.

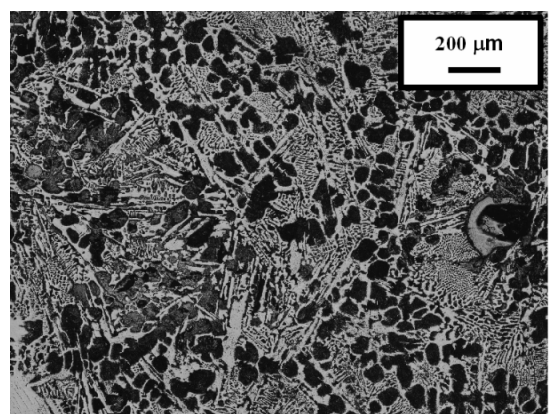

Fig. 5(b). Cross sectional view of Koedo-49. Morphology: hypereutectic cast iron and fayalite.

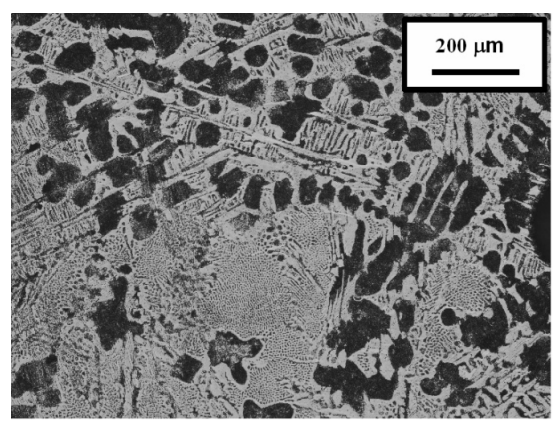

Fig. 5(c). Optical micrograph-2 taken from another region of Koedo-49 sample.

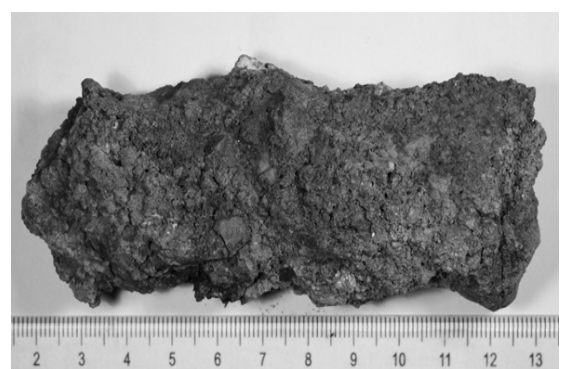

Fig. 6(a). Photograph of the Koedo-50 sample.

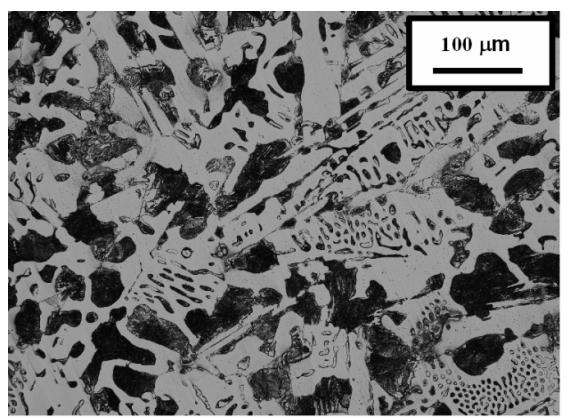

Fig. 6(b). Cross sectional view of Koedo-50. Morphology: pig iron, fayalite and hercinite.

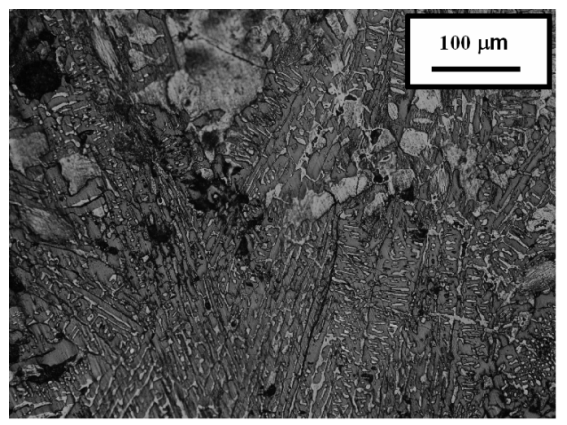

Fig. 6(c). Cross sectional view of boundary region of Koedo-49. Blakish area is mostly non-metallic oxides.

Koedo-39: This specimen contained mostly $\mathrm{FeO}$ including carbon and silica as shown in Table 1. In aggregate the minerals were designated as hypereutectic cast iron and fayalite.

Koedo-40: This specimen was also enriched with $\mathrm{FeO}$ including carbon, silica and alumina. The minerals found in this specimen were designated as a mixture of hypereutectic cast iron, fayalite and hercinite. 
Koedo 47: The average contents of this specimen were $\mathrm{FeO}$ including carbon and silica. A very few amount of sulfur ( $<1.0$ mass $\%)$ was found in some points of the observed area. As a whole a mixture of hypereutectic cast iron and fayalite were observed in this specimen.

Table 2. Vickers micro hardness number (Hv) of the specimens.

\begin{tabular}{lcccccc}
\hline Specimens & Koedo-21 & Koedo-39 & Koedo-40 & Koedo-47 & Koedo-49 & Koedo-50 \\
\hline $\begin{array}{l}\text { Vickers } \\
\text { hardness (Hv) }\end{array}$ & --- & 270 & 528 & --- & 637 & 460 \\
\hline
\end{tabular}

Koedo-49: This specimen contained $\mathrm{FeO}$ including carbon silica and $\mathrm{P}_{2} \mathrm{O}_{5}$. In aggregate the minerals were the mixture of hypereutectic cast iron and fayalite.

Koedo-50: The average contents in this specimen were $\mathrm{FeO}$ including carbon alumina, silica, $\mathrm{P}_{2} \mathrm{O}_{5}, \mathrm{SO}_{3}$ and $\mathrm{CaO}$. Considering the elemental contents it appeared that the minerals were hypereutectic cast iron, fayalite and hercinite. In the boundary region the menerals were pig iron including few amount of fayalite and hercinite.

Vickers micro-hardness test: Vickers micro hardness number was determined for each of the specimens after proper cutting and polishing. Koedo-21 and Koedo-47 specimens were found in the from of porous oxide and brittle. So hardness measurement could not be done for those two specimens. Data were taken from at least ten different points for each specimen and the average results are given in Table 2. The hardness data showed that the specimens were moderately hard unrefined iron. Because the hardness level of refined iron or steel are much higher than those found for the present specimens (Kruss 1999).

\section{CONCLUSIONS}

The artifact unearthed from old forges named, 'Koedo tatara' was observed and analyzed individually. Optical microscopic studies and the elemental analyses revealed that the artifacts contained a variety of minerals having a variety of structural morphology. Those contained major amount of iron oxide along with different kinds of impurity materials with significant amount of carbon except Koedo-21. It is perceptible from the present study that the artifacts analyzed are the ruined products of traditional tatara. Presence of silica in all the specimens justified that these materials were prepared from iron-sand using the traditional techniques of tatara. Iron enrichment of the artifacts also bears the testimony of efficiency of the ancient professionals who were involved in these activities in that period of time. 


\section{ACKNOWLEDGEMENTS}

The authors are thankful to Izumo City Office (Japan) for providing the samples for the study. The authors are also grateful to Prof. Ohba Takuya, Materials Science

Division, Shimane University, Japan for facilitating with the laboratory and experimental facilities during this work.

\section{REFERENCES}

Barnett, M.R., A. Sullivan and R. Balasubramanium. 2009. Materials Characterization 60: 252260.

Das, A. K., Takuya OHBA, Shigekazu MORITO and Muneo YASO. 2010. Materials Science Forum. 654-656: 134-137.

Kruss, George. 1999. Materials Science and Engineering. A273-275: 40-57.

Leon and Hiroko Kapp and Yoshindo Yoshihara. 1987. The Craft of the Japanese Sword - by Kodansha International Ltd., Tokyo Japan, First edition.

Mac, Chesney, J. B. and A. Murau. 1961. American Mineralogist 46: 572.

Mapelli, Carlo, Walter Nicodemi and Riccardo F. Riva. 2007. ISIJ International 47: 1050-1057.

Reibold, M., P. Paufler, A. A. Levin, W. Kochmann, N. Patzke and D. C. Mayer. 2006. Nature 444: 286.

Sherby, Oleg D. 1999. ISIJ International 39(7): 637-648.

Sidney, H Avner. 1998. Introduction to Physical Metallurgy. Tata McGraw-Hill Edition.

Go, Takami, Takuya Ohba, Shigekazu Morito and A. K. Das. 2010. Materials Science Forum 654 656: $138-141$.

(Received revised manuscript on 3 April, 2013) 